\title{
Differentiation in higher education and its consequences for social inequality: introduction to a special issue
}

\author{
David Reimer • Marita Jacob
}

Published online: 16 October 2010

(C) Springer Science+Business Media B.V. 2010

In recent decades institutions of higher education have changed considerably in most European countries. In order to meet the growing demand for higher education, national higher education systems have "diversified" through the creation of second-tier institutions, such as the Polytechnics in Britain or the Fachhochschulen in Germany. There is a large body of research concerned with the sources, development and internal dynamics of institutional differentiation in higher education (e.g. Teichler 1988, Huismann 1995, Meek et al. 1996, Huismann et al. 2007). In many countries higher education institutions also vary in reputation and prestige (e.g. Teichler 2008, Moodie 2009) and in some countries these differences have even been reinforced by educational policy during the last decades. Besides this vertical differentiation of institutions, horizontal differentiation within institutions of higher education can be observed also, i.e. a growing diversification of programmes, courses and fields of study. Different types of programmes such as academic versus professional programmes were introduced or different levels such as Bachelor and Master have been implemented. Not least due to the harmonisation efforts by the so-called 'Bologna process', these forms of differentiation have been accelerated and have become increasingly relevant in European higher education systems.

Although quite a number of recent publications deal with these institutional aspects of diversification in higher education, only a few studies examine the influence of a changing structure on the individual level, e.g. individual behaviour regarding choices and access to higher education, educational careers and labour market outcomes of different institutions. The simultaneous increase in overall participation in post-secondary education in most countries and institutional differentiation are presumably reflected in social selective access to the different institutions of higher education. There are two possible scenarios: Differentiation provides more opportunities in terms of programmes and levels, and less priviledged students are diverted to lower tiers whereas elite institutions remain highly

D. Reimer ( $($ )

Aarhus University, School of Education, Copenhagen, Denmark e-mail: dare@dpu.dk

M. Jacob

University of Mannheim, School of Social Sciences, Mannheim, Germany

e-mail: marita.jacob@sowi.uni-mannheim.de 
socially selective in favour of privileged social strata (e.g. Ayalon and Yogev 2005). Another view would argue that expansion is accompanied by inclusion enhancing chances for less privileged students to participate in all institutions (Arum et al. 2007). These rather general hypotheses have not yet been thoroughly empirically examined. Although many researchers have examined stratification in higher education and its changes over time, a systematic combination of cross-national research focusing on the dynamics within educational careers and the consequences for labour market outcomes given differentiated systems of higher education is still missing. In particular, empirical analyses testing these prevailing assumptions and hypotheses expressed in ongoing public and scientific debates on consequences of differentiation on these different dimensions of social inequality are scarce.

An exception is the recent influential study by Shavit et al. (2007) that draws on largescale individual data to analyse historical change in social inequalities of access to tertiary education by asking how expansion and differentiation affected educational inequality in 15 countries. They find that in highly diversified tertiary systems attendance rates are higher than in systems that are less differentiated even in first tier institutions. Nonetheless, high participation rates are accompanied by greater social selectivity in higher tier institutions than in countries with no or only binary internal differentiation. While the volume by Shavit et al. (2007) focussed on the development of inequality in eligibility and entry into higher education, there are several consequences of differentiation of higher education that remain yet to be examined: differentiation within higher education not only affects initial choice and socially unequal patterns of access to different courses and institutions, but also offers opportunities for specialisation that substantially affect labour market outcomes. Furthermore, in addition to the diversification of tertiary institutions there is also increasing variation in students' lives and study situations. This special issue of Higher Education aims to show the consequences of differentiation in higher education by examining a wide range of outcomes. The seven articles that we have gathered highlight a variety of issues related to access to higher education and beyond in several European countries and the United States. They add to previous research on inequalities in enrolment rates in several respects, e.g. by utilizing a more fine-grained distinction of institutions, examining broader family structures, as well as exploring the association between differentiation and students' employment, and labour market outcomes. Furthermore, the presented papers use relatively new datasets and apply recently developed statistical methods of quantitative empirical analyses.

The first article by Vikki Boliver examines the persistence of social class inequalities in British higher education. By tracing inequalities in access to tertiary education in a period of dramatic expansion from 1960 to 1995, she goes beyond already existing publications that covered shorter periods for the British country case. More specifically she tests the Maximally Maintained Inequality (MMI) and Effectively Maintained Inequality (EMI) hypotheses which contend that educational inequalities tend to persist despite expansion, because those from more advantaged social class backgrounds are better placed to take up new educational opportunities afforded by expansion (MMI) and to secure for themselves qualitatively better kinds of education at any given level (EMI). Her results show that despite the dramatic expansion of higher education quantitative inequalities between social classes in the odds of higher education enrolment proved remarkably persistent, as did qualitative inequalities between social classes in the odds of enrolment in more traditional and therefore higher status degree programmes and 'Old' universities.

The second article by Selina McCoy and Emer Smyth asks a similar question as the authors study the implications of expansion of higher education provision and 
differentiation for social inequality in Ireland. While expansion in overall participation has been dramatic in Ireland, this reflects growth in two distinct higher education sectors. Using nationally representative data from the regular School Leavers' Survey over the period 1980 to 2006, a period of rapid growth in post-school educational participation, this article assesses changes over time in the gender and class profiles of school leaver entrants to these distinct sectors. They find that the initial expansion of higher education in Ireland drew in the higher professional groups in disproportionate numbers to both sectors, widening the gap with other social groups in the late 1980s and early 1990s. This disparity appears to reduce somewhat thereafter as higher professional groups reach near-saturation levels. Furthermore, they do not find diminishing social inequalities in access to higher education past the year 1996, the year when higher education tuition fees were removed.

In the next article Steffen Schindler and David Reimer present a new approach to studying inequality in higher education in Germany by analyzing access to a fine-grained set of postsecondary alternatives. In addition to the differentiation between universities and universities of applied sciences, which attract the major part of higher education students in Germany, they include the university of cooperative education as well as the university of administrative education, two university types that combine firm-based training with tertiary education. These institutions, which they label "semi-tertiary", have largely escaped notice of most stratification researchers so far even though they draw in considerable numbers of students. They find that scholastic performance, expected job security, study duration, monetary costs and preferences for study content considerably contribute to the creation of socially selective choice patterns of post-secondary careers. The characteristics of the semi-tertiary institutions that provide their students with a salary and offer only very short study courses make them a particularly attractive educational alternative that could reduce inequities in access to higher learning in Germany.

The article by Marita Jacob also examines students in Germany, but she departs from traditional approaches to the study of access to tertiary education by inspecting in more detail the effects of sibling sex composition on the graduation of women. Tertiary education is a good test case for testing for sex composition effects due to an unequal distribution of resources among siblings, because the direct costs and opportunity costs of higher education are relatively high compared to those of earlier educational decisions. Using data from the German Life-History Study she shows that it is not the presence of brothers as such, but of older brothers that reduce the chances of their sister's enrolment, in particular for the first tier institution, the universities. Whereas previous research often implicitly assumed that the distribution of resources is planned once a child arrives, her findings indicate that educational decisions are taken successively. Regarding social differences, it turns out that the chances of women to enter higher education are reduced by older brothers even in service class families that were expected to the be most egalitarian.

Josipa Roksa takes a different view on differentiation by analysing students' participation in the labour market during college and whether this influences completion of tertiary degrees in 2 and 4 year institutions in the US. Using data from the National Longitudinal Survey of Youth of 1997 (NLSY97) she finds that students who begin their studies in community colleges as well as students from less advantaged family backgrounds are more likely to dedicate longer hours to paid employment, which has negative consequences for degree attainment. Employment patterns contribute to gaps in degree completion among students from different family backgrounds and to a lesser extent to inequality in degree completion between students who enter community colleges versus 4 year institutions. Her analyses also reveal a notable variation in the relationships between 
employment, family background, and degree attainment across different institutional types and educational credentials.

The contribution by Gianluca Argentin and Moris Triventi simultaneously analyses change over time in the relationship between social origin and participation in tertiary education as well as occupational outcomes of university graduates in Italy. The authors explore whether inequality in access and returns to tertiary education have increased in the recent reform period. More specifically they focus on the differentiation of higher education due to the "Bologna process" and the flexibilization of employment contracts. They draw on data from the Italian Upper Secondary Graduates Survey as well and the University Graduates Survey which cover both pre- and post-reform cohorts of students. Their results show a slight decline in the effect of parents' education on enrolment in tertiary education, together with a reduction and subsequently an increase of inequality in the likelihood of dropping-out of the tertiary system. Inspecting post-tertiary enrolment (such as doctoral programmes), however, they find persistent inequalities. Their analysis of labour market outcomes of graduates shows moderate effects of parents' education on the risks of having an unstable job. Furthermore, they find that labour market outcomes are relatively stable over time.

Finally, Carlo Barone and Luis Ortiz provide an analysis of eight European countries assessing the incidence of over-education by applying standard subjective and objective indicators and a new skill-based indicator of over-education using data from the REFLEX survey of European graduates. With the exception of Spain, the results reveal that overeducation is a minor risk amongst European tertiary graduates. Yet, the contrast between the standard indicators and the skill-based indicator reveals the existence of an overeducation of a moderate kind in countries with high tertiary attainment rates (Norway, Finland and Netherlands). Their results also reveal the importance of higher education differentiation, (i.e. field of study and branch of higher education) for understanding the risk of over-education. Graduates from humanities fields, bachelor courses and vocational colleges are more exposed to over-education, though their disadvantage varies crossnationally to a significant extent.

While a synthesis of all results is beyond what can be provided in this short summarygiven the different countries, methodologies and research questions considered-a few insights can be highlighted: In most of the analyses it turns out that differentiation in higher education actually leads to an inclusion of less privileged students but at the same time higher tier institutions have remained socially selective (e.g. McCoy and Smyth, Boliver). The presented analyses also showed that when studying inequality in access, it is a worthwhile effort to go beyond rough dichotomies (first-tier versus second-tier) and consider a more fine-grained schema of tertiary institutions which also includes smaller university types such as the semi-tertiary intuitions in Germany that might attract different strata of the population (e.g. Schindler and Reimer). Besides analysing the impact of parental class and education on access to higher education as has been done in previous research, two analyses showed that differentiation interacts with other dimensions of students' family and living situation such as working during one's study (Roksa) or the broader family structure (Jacob) to produce unequal outcomes across socioeconomic groups.

Furthermore, higher education differentiation is not only important at the level of high versus low status institutions but differentiation in degree levels or field of study needs to be considered as well (Barone and Ortiz). Last but not least, differentiation in higher education is a phenomenon that can but does not necessarily lead to a change in the 
relationship between social origins and participation in higher education (Argentin and Triventi).

Several further questions emerge from the given contributions: For example, future research on differentiation in higher education and its consequences for social inequality needs to study labour market outcomes in more detail. Indeed, we have found social inequalities in access and indicators for unequal labour market chances, but this finding does not necessarily imply that differentiation always leads to different life chances for students from different social origin. This assumption has to be tested by further empirical research to find out whether different degrees actually lead to different employment opportunities, labour market outcomes, as well as consequences for other life domains like partnership formation and fertility.

The articles of this special issue were prepared by members of a research team that has been part of a large research network funded by the sixth framework program of the European Union, called Economic Change, Quality of Life and Social Cohesion (Equalsoc) whose support we gratefully acknowledge. We thank all participants of the research group's meetings in Mannheim, Tallinn and Copenhagen and the referees for valuable comments and suggestions.

\section{References}

Arum, R., Gamoran, A., \& Shavit, Y. (2007). More inclusion than diversion: Expansion, differentiation, and market structure in higher education. In Y. Shavit, R. Arum, \& A. Gamoran (Eds.), Stratification in higher education: A comparative study. Stanford, CA: Stanford University Press.

Ayalon, H., \& Yogev, A. (2005). Field of study and students' stratification in an expanded system of higher education: The case of Israel. European Sociological Review, 21(3), 227-241.

Huismann, J. (1995). Differentiation, diversity, and dependency in higher education: A theoretical and empirical analysis. Utrecht: Lemma.

Huismann, J., Meek, L., \& Wood, F. (2007). Institutional diversity in higher education: A cross-national and longitudinal analysis. Higher Education Quarterly, 61(4), 563-577.

Meek, L. V., Goedegebuure, L., Kivinen, O., \& Rinne, R. (Eds.). (1996). The mockers and the mocked: Comparative perspectives on differentiation, convergence and diversity in higher education. Pergamon: IAU Press.

Moodie, G. (2009). 'Four tiers'. Higher Education, 58(3). doi: 10.1007/s10734-008-9195-4.

Shavit, Y., Arum, R., \& Gamoran, A. (Eds.). (2007). Stratification in higher education: A comparative study. Stanford: Stanford University Press.

Teichler, U. (1988). Changing patterns of the higher education system. London: Jessica Kingsley Publishers.

Teichler, U. (2008). 'Diversification? trends and explanations of the shape and size of higher education'. Higher Education, 56, 349-379. 